\title{
Janine Firges
}

Gradation als ästhetische Denkform des 18. Jahrhunderts 


\title{
Quellen und Forschungen zur Literatur- und Kulturgeschichte
}

\author{
Begründet als \\ Quellen und Forschungen \\ zur Sprach- und Kulturgeschichte \\ der germanischen Völker \\ von \\ Bernhard Ten Brink und \\ Wilhelm Scherer \\ Herausgegeben von \\ Ernst Osterkamp und \\ Christiane Witthöft
}

$96(330)$

De Gruyter 


\section{Gradation als ästhetische Denkform des 18. Jahrhunderts}

Figuren der Steigerung, Minderung und des Crescendo

Janine Firges

De Gruyter 
Dieses Buch wurde gefördert mit Mitteln des im Rahmen der Exzellenzinitiative des Bundes und der Länder eingerichteten Exzellenzclusters der Universität Konstanz „Kulturelle Grundlagen von Integration“.

Geringfügig überarbeitete Version der Dissertation angenommen an der Universität Konstanz, Referentinnen: Prof.in Dr. Juliane Vogel, Prof.in Dr. Cornelia Zumbusch, Tag der mündlichen Prüfung: 21. Juli 2016

\author{
ISBN 978-3-11-059645-8 \\ e-ISBN (PDF) 978-3-11-060296-8 \\ e-ISBN (EPUB) 978-3-11-060356-9 \\ ISSN 0946-9419
}

Library of Congress Control Number 2018959699

Bibliografische Information der Deutschen Nationalbibliothek

Die Deutsche Nationalbibliothek verzeichnet diese Publikation in der Deutschen Nationalbibliografie; detaillierte bibliografische Daten sind im Internet über http://dnb.dnb.de abrufbar.

(C) 2019 Walter de Gruyter GmbH, Berlin/Boston

Satz: Dörlemann Satz, Lemförde

Druck und buchbinderische Verarbeitung: Hubert \& Co. GmbH \& Co. KG, Göttingen

www.degruyter.com 

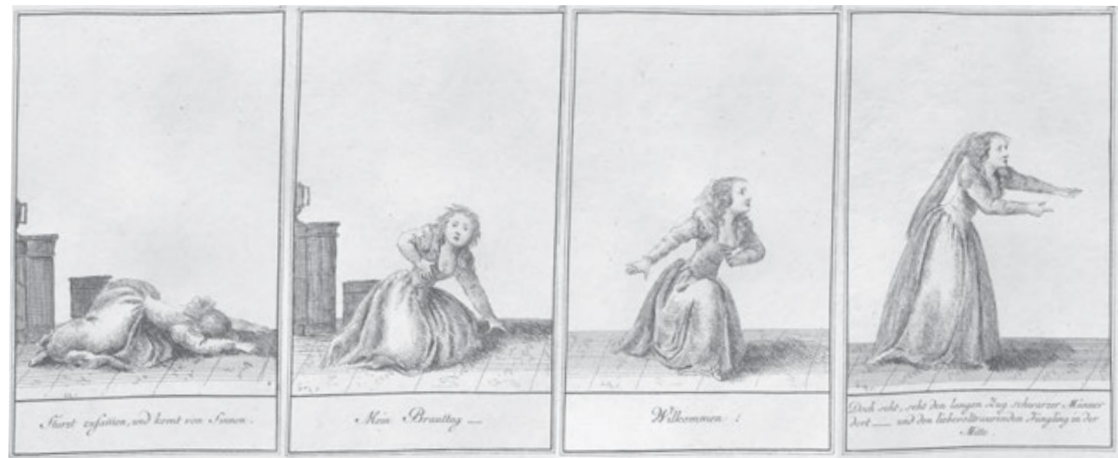

Joseph Franz von Goetz: Versuch einer zalreichen Folge leidenschaftlicher Entwürfe für empfindsame Kunst-und Schauspiel-Freunde, 1783. 

Meiner Mutter Renate aus Liebe zur Musik, meinem Vater Jean aus Liebe zur Literatur gewidmet 
